\title{
Use of the Rumination Profile Through Collar Sensors for Mastitis Diagnosis in Dairy Cows
}

\author{
Ana Paula Schmidtt ${ }^{1}$, Laura Valadão Vieira ${ }^{1}$, Antônio Amaral Barbosa ${ }^{2}$, Leonardo Marins ${ }^{3}$, \\ Marcio Nunes Corrêa ${ }^{4}$, Francisco Augusto Burkert Del Pino ${ }^{5}$, Cássio Cassal Brauner ${ }^{6}$, \\ Viviane Rohrig Rabassa ${ }^{4}$, Josiane de Oliveira Feijón ${ }^{1}$ \& Eduardo Schmitt ${ }^{4}$
}

\begin{abstract}
Background: Mastitis is an inflammatory disease of the mammary gland, mostly associated with bacterial infections. It is responsible for great economic losses due to decreased milk yield, discarded milk, milk composition alterations and treatment costs, besides it impairs the animal health and welfare. The rumination time is an important behavioral marker and its assessment can be used as an early diagnosis tool, which can improve cure rate. Therefore, the aim of the present study was to evaluate the sensitivity of behavior monitoring system collars in the diagnosis of mastitis and the average rumination time (RT) of Holstein cows during the healthy period and affected by the disease.

Materials, Methods \& Results: The study was conducted on a commercial property located in the municipality of Rio Grande, Rio Grande do Sul, Brazil. The RT data from 39 multiparous Holstein cows with an average milk yield of $38.4 \mathrm{~L} /$ day was collected. RT monitoring was performed using C-Tech1 collars combined with CowMed® software, which assess behavior data from the animals and emits warning signals when it finds abnormalities in any parameter. In order to verify whether the animals were determined correlated with diseases, the sensitivity of the data was evaluated, when the system had given the alert to animals considered ill, they underwent to a further clinical evaluation performed by a veterinarian to confirm the diagnosis. From the diagnosis, the cows were divided into subclinical mastitis (SM) and clinical mastitis $(\mathrm{CM})$ groups. SM was detected by the California Mastitis Test (CMT) and cows that were graded $1(++), 2(++)$ or $3(+++)$ without the presence of any other clinical sign were assigned to the SM group. CM was assessed by observation of abnormalities in milk such as changes in color and consistency, as well as the presence of lumps, clots or blood; and clinical examination of the udder was performed for detection of hot, hard, swollen or painful quarters. Thereafter, variations in the mean RT between the healthy ( 15 days) and sick periods (days when there was an alert) were evaluated. For the identification of the etiological agents involved in the cases of $\mathrm{CM}$, microbiological cultures were performed on Accumast ${ }^{\circledR}$ plates with milk samples, which were incubated at a temperature of $37^{\circ} \mathrm{C}$ and the diagnosis of the pathogens were performed after 16 hours of incubation. During the study, 57 cases of mastitis were observed, 42 were SM and 15 were CM. The sensitivity of the system, which is the ability to detect positive cases of the disease, was $73.8 \%$ for SM and $73.3 \%$ for MC. The RT of the animals were compared individually during the healthy period with the sick period and it was observed that SM reduced the RT by $5.33 \%$ whereas MC reduced the RT by $14.9 \%$.

Discussion: The maximum RT values were lower during the disease period in relation to the period in which the animals were healthy, for both SM and CM, which is due to the fact that the disease is responsible for causing inappetence in animals, among other clinical signs, therefore, reducing feed consumption. The lowest variation in RT, between the healthy and sick period, was observed in cases of SM, which was already expected, since the clinical form tends to cause more discomfort to the animals. As for the main etiological agents involved in the clinical condition, Streptococcus agalactiae and S. uberis were detected. In view of the above, the evaluation of the mean RT of multiparous dairy cows was efficient in the predictive diagnosis of SM and CM up to two days before the onset of the disease. In addition, the variability of this result demonstrated that animals with subclinical cases presented less fluctuation in RT.
\end{abstract}

Keywords: cow health, rumination time (RT), technology, udder. 


\section{INTRODUCTION}

Mastitis is characterized by an inflammatory condition in the mammary gland, the main cause of which is bacterial in origin [17]. Its involvement can occur in the subclinical (SM) and clinical (MC) forms. CM can be mild (abnormal milk), moderate (abnormal milk and changes in the udder) and severe (with systemic signs, such as pyrexia, dehydration and lack of appetite) [25].

The disease causes economic losses and has a high incidence, the study by Langoni [13], estimated that for each case of clinical mastitis, there are 20 and 50 subclinical cases of the disease. And the losses are due to the disposal of milk, reduced production, lower milk quality, treatment and premature disposal of animals [5], reaching an annual expenditure of R \$ 277,411.25 in a herd of 100 cows [16].

Early diagnosis plays an important role in reducing the negative effects of mastitis [23]. Among the tools to detect this disease, rumination sensors, such as those used in C-Tech collars (Chip inside), have become effective alternatives to identify mastitis and other diseases in early stages [23]. In this sense, the objective of the present study was to evaluate the average rumination time (RT) of dairy Holstein cows during the healthy period and affected by SM and CM through C-TECH (Chip-inside) rumination collars, as well as how to detect sensitivity of rumination collars C-TECH1 in the detection of SM and CM.

\section{MATERIALS AND METHODS}

\section{Location}

The study was conducted in a commercial property located in city of Rio Grande, the south of Rio Grande do Sul, Brazil, (32 ${ }^{\circ} 1$ ' 60" south, 52 5' 55" West), between June and November 2018.

\section{Animals and diet}

One hundred and twenty-eight (128) multiparous Holstein cows with an average milk yield of 38.4 liters / day were assigned for this study. The animals were housed in a Compost Barn, had free access to water and were fed twice a day, in the morning and afternoon. The diet consisted of corn silage, pre-dried ryegrass, moist and concentrated grain, without nutritional changes during the whole study period.

\section{$R T$ monitoring}

The system used to monitor the animal's RT was the C-TECH ${ }^{1}$ collars (Chip-Inside) and the
CowMed $^{\circledR 2}$ software, which captures data from the collar every hour. The C-Tech (Chip inside) ${ }^{1}$ collar sensors have an accelerometer that measures rumination, physical activity, and bovine inactivity every hour. The system consists of the C-Reader and management software, which can generate a behavioral pattern for each animal in the herd and also an average pattern for the entire herd through behavioral data. Whenever the system detects an inconsistency in the animal behavioral pattern, it gives an alert to identify that the animal might be sick.

\section{Experimental design}

From the initial 128 animals, only 39 (30.46\%) were suitable to enter the experiment, since they met the following criteria: (1) the animals should be monitored by the CowMed ${ }^{\circledR 2}$ system platform; (2) their rumination pattern changes should be reported by the system; (3) they should be healthy for at least 15 days prior to the system alert; (4) SM diagnosis should be performed by the Veterinarian through the California Mastitis Test (CMT), besides the system alert; (5) CM diagnosis should be performed by the Veterinary through foremilking associated with the system alert. After diagnosis, the animals were enrolled in the Group SM or Group CM, according to the severity grade.

During the healthy period, the rumination rates were calculated as the mean of 15 days, while during the sick period, the rumination rates were calculated as the mean of the days under the system's alert. The animals were considered ill until their rumination patterns returned back to normal.

Further, the average values of maximum and minimum rumination and the variation occurring in each period were verified.

To enhance the results, it was considered for analysis purposes, the true positive cases, true negatives, false positives and false negatives, in order to affirm the efficiency of the monitoring system. Being:

I - True Positive (VP): Those animals that had an alert detected by the system and had their diagnosis confirmed by the Veterinarian through foremilking and CMT;

II - True Negative (VN): Those animals that did not have an alert and weren't diagnosed with any disease by the Veterinarian;

III - False Positive (FP): Those animals that had an alert and were diagnosed with another disease instead of mastitis; 
IV - False Negative (FN): Those animals that did not have an alert and were diagnosed with any disease by the Veterinarian.

Sensitivity calculation (Formula 1) was performed to assess the capacity of the RT monitoring system to detect cases of clinical and subclinical mastitis [3].

tives) $\mathrm{x} 100$

True positives/ (true positives + false nega-

\section{Identification of the etiologic agent that causes mastitis}

Microbiological cultures of milk samples from the animals with CM were performed to identify the etiological agents that were causing mastitis. The on-farm method was applied, in which a milk sample from the affected mammary gland quarter is sown on a tripartite Accumast ${ }^{\circledR 3}$ plate. Each plate has three distinct and specific culture media for the growth of certain bacteria. The agents were identified on the farm according to the bacterial colony color following the company instructions.

Once diagnosis had been confirmed by the veterinarian after the C-TECH1 collars alert, milk was collected in a sterile bottle and, subsequently, a sample was sown on the plates using a swab and these were stored in an incubator at $37^{\circ} \mathrm{C}$. After the first 16 $\mathrm{h}$ of sowing, colonies were identified according to the culture medium, being they: substrate 1 specific for the growth of gram-negative bacteria (Klebsiella spp., E. coli and Pseudomonas spp.); substrate 2 (Streptococcus spp., Lactococcus spp. and Enterococcus spp.); substrate 3 (Staphylococcus aureus and Staphylococcus spp.).

\section{Statistical analysis}

The normality of the data was verified by the Shapiro Wilk test. The Levene test was used to verify the homoscedasticity of the variance. Parametric data were analyzed using the $\mathrm{SAS}^{4}$ software, using the one- way ANOVA test for analysis of variance, where the difference between the average number of cases of the disease and the period (healthy and sick) was evaluated. $P<0.05$ was considered significant.

\section{RESULTS}

During the study period, 57 cases of mastitis were observed, in which 42 were SM and 15 were CM. The C-TECH collar detection sensitivity was $73.8 \%$ (31 cases) for SM and $73.3 \%$ for CM (11 cases). The animals average RT for both groups in each period are described (Table 1).

It was found that the animals average RT in the SM group tended to be lower during the sick period compared to the healthy period representing a 5.33\% reduction on the evaluated parameter when the periods were compared. The average time in which the animals in the SM group remained ill throughout the study period was 7.5 days compared to 6.5 in the CM group.

There was a decrease in the cows average RT with $\mathrm{CM}(P=0.0014)$ during the healthy period, showing a decrease of $14.85 \%$ when periods were compared. The maximum and minimum values of rumination and the average variation of this parameter were verified in each group and period studied (Table 2).

There was a decrease in the maximum rumination time $(\mathrm{RT})$ in the $\mathrm{SM}(P=0.002)$ and $\mathrm{CM}(P=$ $0.010)$ groups during the period when the animals were sick. Regarding the minimum RT, the cows in the CM group tended to have a lower RT $(P=0.08)$ compared to healthy cows. The average variation of RT between the maximum and minimum values, showed a difference for the SM group $(P=0.015)$ with lower fluctuations of the parameter during the ill period.

In addition, Streptococcus agalactiae and $S$. uberis were the etiologic agents causing CM, whereas in the SM cases the agent verification test was not performed according to the farm protocol.

Table 1. Average Rumination Rates \pm Standard Error, for the Subclinical Mastitis (SM) and Clinical Mastitis (CM) groups in each period during the months from July to November 2018.

\begin{tabular}{cccc}
\hline Group & & Period & $P$-value \\
\hline & Healthy & Sick & \\
\cline { 2 - 3 } SM & $581.50 \pm 11.88$ & $550.48 \pm 11.88$ & 0.068 \\
CM & $587.41 \pm 16.69$ & $500.30 \pm 16.69$ & 0.001 \\
\hline
\end{tabular}


Table 2. Values found of maximum and minimum rumination and its variation \pm Standard Error, of the Subclinical Mastitis (SM) and Clinical Mastitis (CM) groups of each period during the months from July to November 2018.

\begin{tabular}{ccccc}
\hline \multirow{2}{*}{ Group } & Rumination Rate $(\mathrm{min} / \mathrm{d})$ & \multicolumn{2}{c}{ Period } & \multirow{2}{*}{$P$-value } \\
\cline { 3 - 4 } & & Healthy & Sick & 0.002 \\
\multirow{3}{*}{$\mathrm{SM}$} & Maximum & $698.97 \pm 11.08$ & $648.11 \pm 11.38$ & 0.675 \\
& Minimum & $431.08 \pm 21.45$ & $444.00 \pm 22.02$ & 0.015 \\
\hline \multirow{3}{*}{$\mathrm{CM}$} & Variation & $267.90 \pm 19.70$ & $198.74 \pm 19.95$ & 0.010 \\
& Maximum & $694.18 \pm 19.54$ & $611.11 \pm 21.60$ & 0.084 \\
& Minimum & $452.73 \pm 20.20$ & $397.78 \pm 22.33$ & 0.514 \\
\hline
\end{tabular}

\section{DISCUSSION}

Researchers approach that the maximum physiological time of rumination is about 10 to $12 \mathrm{~h} / \mathrm{d}$, in cattle fed high fiber diets [4], but the majority of dairy cows fed mixed diets ruminate by less time [29]. Therefore, lactating dairy cows spend around $7 \mathrm{~h}$ a day on rumination (420 min) [2]. Studies have shown an association between a decreased RT and clinical and subclinical health disorders [7]. Likewise, our study has shown that during the ill period the RT was reduced by $5.33 \%$ for SM and by $14.85 \%$ for CM, which could be related to the challenge faced by the animals with mastitis.

Although few studies have been carried out on this subject, our findings are similar to others already published, which found an average RT value of 436 $\mathrm{min} / \mathrm{d}$, ranging from 236 to $610 \mathrm{~min} / \mathrm{d}$ in a dairy herd of 179 animals [30]. In one study that compared a group of healthy cows with a group of sick cows, a large variation in TR was found between cows and that the TR began to differ from the normal pattern until 2 weeks before the diagnosis of mastitis [12]. Still, other studies have noted lower RT in sick animals, when comparing cows that had some type of health disorder with healthy cows $[10,27]$. Other authors, when evaluating behavioral data before the appearance of health problems, found that the TR parameter helped to diagnose diseases early before the animals were clinically affected [11]. It was detected in our study, a 31 and $87 \mathrm{~min} / \mathrm{d}$ reduction in the average RT associated with the presence of SM and CM, respectively. In our study, a reduction of 31 and $87 \mathrm{~min} / \mathrm{d}$ was detected in the mean RT associated with the presence of MS and MC, respectively. These results exceed the observations of other studies that found a $10.4 \mathrm{~min} / \mathrm{d}$ reduction in RT of dairy cattle with mastitis, but are similar to other findings that found an $80 \mathrm{~min} / \mathrm{d}$ reduction in TR when they associated this parameter at the beginning subclinical disease [15,28].

Some researchers have detected a $397 \mathrm{~min} / \mathrm{d}$ lower RT in cows diagnosed with CM compared to healthy cows [28]. Our results corroborate the study mentioned, where the same group presented the same values, suggesting that the use of alerts generated based on this indicator can be used as a tool to diagnose both SM and CM. Furthermore, some studies have evaluated average RT in cows with induced clinical mastitis or challenged with membrane lipopolysaccharide (LPS) [6] and have shown reductions in RT varying 2 to $7 \mathrm{~h} / \mathrm{d}$ before diagnosis or disease induction [20].

It was observed that the maximum and minimum RT in this study were decreasing at the diagnosis moment. In addition, the existing average variability was lower in cases affected by SM. Minor variations in this group may explain that these animals have more chances to get their rumination patterns back to normal and overcome the discomfort caused by a subclinical disease.

Streptococcus agalactiae is one of the main bacteria that causes mastitis in contagious form These microorganisms survive inside the host and may be present in the body of the animal [24]. This pathogen is mandatory in the bovine mammary gland and due to its characteristics, in most cases have highly contagious behavior [9]. Streptococcus uberis is present in several sources of the farm environment, such as contaminated water, feces, soil, organic materials used as bedding, the animal itself, the milking equipment and humans [14]. During the bacterial infection, many cytokines are released to modulate the inflammatory and immune responses. The Tumor necrosis factor (TNF- $\alpha$ ) cytokines can be used as biomarkers for an inflammatory 
condition [1]. Although it has a plasma half-life of only $20 \mathrm{~min}$, it is capable of causing important metabolic and hemodynamic changes such as activating other cytokines included the Interleukin-6 (IL-6), an important mediator in the release of acute phase proteins by hepatocytes during painful stimuli [22].

Therefore, a possible cause of the reduction in the animals average RT might be due to the large release of those inflammatory mediators, which regulate the release of inflammatory cells on the injured tissue mediated by the hypothalamus, possibly activating the satiety center [8]. Hence, it can reduce the animal feed intake and affect the RT.

Technologies capable of detecting rumination patterns as well as other behavior aspects are being increasingly incorporated into production systems and they can become part of the routine of dairy farms. Lower RT is a promising indicator to provide information on health risks and to monitor the metabolic conditions associated with diseases [26]. These animal monitoring technologies allow the identification of potential problems such as mastitis, which is still one of the most concerning diseases for dairy farmers. The vast information generated by the sensors is a precious resource that can potentially be used to reduce production losses, adopting different strategies, one being the establishment of treatments that reduce the disease negative effects on the animal's productive potential [21].

\section{CONCLUSION}

The average RT of multiparous dairy cows proved to be efficient in the predictive diagnosis of MS and CM up to 2 days before the disease onset. In addition, its variability demonstrated that animals with subclinical cases had lower fluctuations when sick. In addition, the animals presented mastitis caused by Streptococcus agalactiae and S. uberis.

\section{MANUFACTURERS \\ ${ }^{1}$ Chip Inside. Santa Maria, RS, Brazil. \\ ${ }^{2}$ CowMed. Santa Maria, RS, Brazil. \\ ${ }^{3}$ Fera Animal Health LCC. Ithaca, NY, USA. \\ ${ }^{4}$ SAS Institute Inc. Cary, NC, USA.}

Ethical approval. This research was approved by the Ethical Committee for Animal Use of the Universidade Federal of Pelotas - UFPel (under protocol 22166).

Declaration of interest. The authors report no conflicts of interest. The authors alone are responsible for the content and writing of the paper.

\section{REFERENCES}

1 Bingham O.C. 2002. The pathogenesis of rheumatoid arthritis: pivotal citokynes involved in bone degradation and inflammation. The Journal of Rheumatology. 65(29): 3-9.

2 Beauchemin A.K. 2018. Invited review: Current perspectives on eating and rumination activity in dairy cows. Journal of Dairy Science. 101(6): 4762-4784. https://doi.org/10.3168/jds.2017-13706.

3 Côrtes J.A. 1993. Epidemiologia: Conceitos e Princípios Fundamentais. São Paulo: Livraria Varela, pp.133-138.

4 De Boever J.L., Andries J.I., De Brabander D.L., Cottyn B.G. \& Buysse F.X. 1990. Chewing activity of ruminants as a measure of physical structure - A review of factors affecting it. Animal Feed Science and Technology. 27(4): 281291. https://doi.org/10.1016/0377-8401(90)90143-V.

5 Demeu F.A., Lopes M.A., Costa G.M., Rocha C.M.B.M. \& dos Santos G. 2016. Efeito da produtividade diária de leite no impacto econômico da mastite em rebanhos bovinos. Boletim de Indústria Animal. 73(1): 53-61. http://dx.doi. org/10.17523/bia.v73n1p53.

6 Fitzpatrick C.E., Chapinal N., Petersson-Wolfe C.S., DeVries T.J., Kelton D.F., Duffield T.F. \& Leslie K.E. 2013. The effect of meloxicam on pain sensitivity, rumination time, and clinical signs in dairy cows with endotoxin-induced clinical mastitis. Journal of Dairy Science. 96(5): 2847-2856. https://doi.org/10.3168/jds.2012-5855.

7 Gáspárdy A., Efrat G., Bajcsy A.C. \& Fekete S.G. 2014. Electronic monitoring of rumination activity as an indicator of health status and production traits in high-yielding dairy cows. Acta Veterinaria Hungarica. 62(4): 452-462. https:// doi.org/10.1556/avet.2014.026.

8 Kunkel E.J. \& Butcher E.C. 2002. Chemokines and the tissue-specific migration of lymphocytes. Immunity. 16(1): 1-4. https://doi.org/10.1016/S1074-7613(01)00261-8.

9 Keefe G.P. 2012. Update on control of Staphylococcus aureus and Streptococcus agalactiae for management of mastitis. The Veterinary Clinics of North America: Food Animal Practice. 28(2): 203-216. https://doi.org/10.1016/j. cvfa.2012.03.010. 
10 Kaufman E.I., Leblanc S.J.B., Mcbride W.T. \& DeVries T.J. 2016. Association of rumination time with subclinical ketosis in transition dairy cows. Journal of Dairy Science. 99(7): 5604-5618. https://doi.org/10.3168/jds.2015-10509.

11 King M.T.M., Dancy K.M., LeBlanc S.J., Pajor E.A. \& DeVries T.J. 2017. Deviations in behavior and productivity data before diagnosis of health disorders in cows milked with an automated system. Journal of Dairy Science. 100(10): 8358-8371. https://doi.org/10.3168/jds.2017-12723.

12 King M.T.M., LeBlanc S.J., Pajor E.A., Wright T.C. \& DeVries T.J. 2018. Behavior and productivity of cows milked in automated systems before diagnosis of health disorders in early lactation. Journal of Dairy Science. 101(5): 4343-4356. https://doi.org/10.3168/jds.2017-13686.

13 Langoni H. 2013. Qualidade do leite: utopia sem um programa sério de monitoramento da ocorrência de mastite bovina. Pesquisa Veterinária Brasileira. 33(5): 620-626.

14 Langoni H., Guiduce M.V.S., Nóbrega D.B., Silva R.C.D., Richini-Pereira V.B., Salina A. \& Guimarães F.D.F. 2013. Research of Klebsiella pneumoniae in dairy herds. Pesquisa Veterinária Brasileira. 35(1): 9-12. https://doi. org/10.1590/S0100-736X2015000100003.

15 Liboreiro D.N., Machado K.S., Silva P.R., Maturana M.M., Nishimura T.K., Brandão A.P., Endres M.I. \& Chebel R.C. 2015. Characterization of peripartum rumination and activity of cows diagnosed with metabolic and uterine diseases. Journal of Dairy Science. 98(10): 6812-6827. https://doi.org/10.3168/jds.2014-8947.

16 Lopes M.A., Demeu F.A., Rocha C.M.B.M., Costa G.M., Franco Neto A. \& Santos G.D. 2012. Avaliação do impacto econômico da mastite em rebanhos bovinos leiteiros. Arquivos do Instituto Biológico. 79(4): 477-483. https:// doi.org/10.1590/S1808-16572012000400003.

17 Lopes B.C., Manzi M.P. \& Langoni H. 2018. Etiologia das mastites: pesquisa de micro-organismos da classe Mollicutes. Veterinária e Zootecnia. 25(2): 173-179.

18 Müller R. \& Schrader L.A. 2003. New method to measure behavioural activity levels in dairy cows. Applied Animal Behaviour Science. 83(4): 247-258. https://doi.org/10.1016/S0168-1591(03)00141-2.

19 Olde Riekerink R.G.M., Barkema H.W., Kelton D.F. \& Scholl D.T. 2008. Incidence rate of clinical mastitis on Canadian dairy farms. Journal of Dairy Science. 91(4): 1366-1377. https://doi.org/10.3168/jds.2007-0757.

20 Paudyal S., Maunsell F.P., Richeson J.T., Risco C.A., Donovan D.A. \& Pinedo P.J. 2018. Rumination time and monitoring of health disorders during early lactation. Animal. 12(7): 1484-1492. https://doi.org/10.1017/S1751731117002932.

21 Petzer I.M., Etter E.M., Donkin E.F., Webb E.C. \& Karzis J. 2017. Epidemiological and partial budget analysis for treatment of subclinical Staphylococcus aureus intramammary infections considering microbiological and cytological scenarios. Preventive Veterinary Medicine. 148: 66-77. https://doi.org/10.1016/j.prevetmed.2017.10.005.

22 Raeburn C.D., Sheppard F., Barsness K.A., Arya J. \& Harken A.H. 2002. Cytokines for surgeons. The American Journal of Surgery. 183(3): 268-273. https://doi.org/10.1016/S0002-9610(02)00781-X.

23 Reis E.M.B. \& Lopes M.A. 2014. Métodos automatizados de diagnóstico de mastite em vacas leiteiras: uma revisão. $A r$ quivos de Ciências Veterinária e Zoologia da UNIPAR. 17(3): 199-208. https://doi.org/10.25110/arqvet.v17i3.2014.4945.

24 Rodrigues T.P., Coelho M.G., Santos A.P., Costa I.S. \& Cortez M.A.S. 2018. Bovine Mastitis- Influence in the Production, Composition and Industrial yield of Milk and Dairy products. Arquivos de Pesquisa Animal. 1(1): 14-36.

25 Scott P.R., Penny C.D. \& Macrae A.I. 2011. Mastitis and teat Diseases. In: Cattle Medicine. London: Manson Publishing, pp.216-218.

26 Soriani N., Trevisi E. \& Calamari L. 2012. Relationships between rumination time, metabolic conditions, and health status in dairy cows during the transition period. Journal of Animal Science. 90(12): 4544-4554.

27 Schirmann K., Weary D.M., Heuwieser W.N., Chapinal R.L.A., Cerri M.A.G. \& Von Keyserlingk M.A.G. 2016. Short communication: Rumination and feeding behaviors differ between healthy and sick dairy cows during the transition period. Journal of Dairy Science. 99(12): 9917-9924. https://doi.org/10.3168/jds.2015-10548.

28 Stangaferro M.L., Wijma R., Caixeta L.S., Al-Abri M.A. \& Giordano J.O. 2016. Use of rumination and activity monitoring for the identification of dairy cows with health disorders: Part III. Metritis. Journal of Dairy Science. 99(9): 7422-7433. https://doi.org/10.3168/jds.2016-11352.

29 Watt L.J., Clark C.E.F., Krebs G.L., Petzel C.E., Nielsen S. \& Utsumi S.A. 2015. Differential rumination, intake, and enteric methane production of dairy cows in a pasture-based automatic milking system. Journal of Dairy Science. 98(10): 7248-7263. https://doi.org/10.3168/jds.2015-9463.

30 White R.R., Hall M.B., Firkins J.L. \& Kononoff P.J. 2017. Physically adjusted neutral detergent fiber system for lactating dairy cow rations. I: Deriving equations that identify factors that influence effectiveness of fiber. Journal of Dairy Science. 100(12): 9551-9568. ttps://doi.org/10.3168/jds.2017-12765. 